\title{
CASE REPORTS.
}

\author{
Dr. W. D. Br,ACK, St. Louis.
}

Case I. Hemoglobinuria following peri-tonsillar abscess and recurring after other infections: In 1905 , I was called to attend a patient, male, 1.2 years of age, apparently healthy. I-Ie had had most of the infections diseases of childhood with the exception of scarlet fever. 'The child's tonsils and aclenoids were operated upon three years previous to the present illness but were only partly removed. Present illness began with a sore throat, chills and fever. About twenty-four hours after onset the tonsils showed a typical follicular tonsillitis; after two or three days the follicles disappeared but the right tonsil began to get painful and swollen. In two or three days the patient had a well-developed peri-tonsillar abscess which was opened the sixth day and pus evacuated. About this time the patient showed signs of sepsis. Urine showed a change, dark amber at first and after twenty-four hours reddishbrown, was slightly decreased in quantity. After rest and eliminative treatment the turine gradually cleared, in about two weeks. Examination of the urine by two microscopists showed a quantity of albumen hyaline and grantular casts; the latter disappeared after a few days. Another microscopist reported hemoglobin but no red blood cells. After two years of treatment by diet anci change to a southern climate the patient's urine became free of albumen and he fully recovered.

In 1908, three years after the first attack, the patient again had an infection simulating grip. Although there was only a mild pharyngitis and tonsillitis the urine again showed a change in color after twenty-six hours. Examination of urine chemically. showed albumen and casts which latter disappeared after seven or ten days. The pathologist who reported the finding of hemoglobin during his first illness reported a similar condition in this attack. Two other doctors examined the urine and confirmed his findings. This attack ran a course similar to the first one, requiring many months before the urine showed no trace of albumen.

During the next five years the patient was in good health except for frequent colds which produced a small amount of albumen in the urine but no casts or hemoglobin and which disappeared after a week or two. 
In February or March, 1913, he again had an attack which came on a little different from the others. In this attack the first symptoms were dryness of the throat with dysphagia but no tonsillitis. Buccal membrane and that of pharynx showed a pale, red color; tongue dry and rough. Urine findings identical to those of prior attacks. This attack was severe and the patient showed much prostration and headache which were relieved by eliminative treatment. Although this attack was severe the urine cleared much more quiclily and the patient was fully recovered in a few weeks.

In January, 1914, the patient developed typical follicular tonsillitis followed by peri-tonsillar abscess. Pus was evacuated eight days after the onset of the peri-tonsillar infection. Again the urine showed hemoglobin, albumen and a few casts. After a couple of weeks the patient is again apparently normal.

All attacks practically ran the same course and in all probability came from the throat infection. One particular striking symptom noted during each attack was the slight icterus and slowing of pulse rate which ranged between fifty and sixty per minute. There was no edemá or any general symptoms that often accompanies acute nephritis. The blood was examined for plasmodia each time and none found. A Wasscrmann tesit of patient's blood was not made.

Recently W. W. Young, of Boston, wrote an article which appeared in Vol. XITI, No. 5, of the Joumal A. M. A., in which he cluotes Cook who states that 90 per cent of hemoglobinuria gives a positive Wassermann reaction. Now in this case I am positive the attack followed throat infection.

The father of the patient had two attacks of iritis three or four yeirs prior to a tubercular involvement of the lungs but no history of lues. The iritis was diagnosed rheumatic by a competent oculist.

I have repeatedly advised the complete removal of the tonsils and adenoids but the mother of the patient will not consent.

Case 2: Iuxation of the faucial tonsil: Patient, Russian who could not speak Innglish, aged 44 years, came to City Hospital clinic, suffering from a sore throat.

An examination revealed an acute tonsillitis and pharyngitis. The left tonsil was spherical and was lying in a cup-shaped cavity. 'This cavity was supported by a short, thick column of fibrous and lymphoid tissue at the inferior tonsillar fossa, filling it about onethird of its height. Upon using a probe, I discovered it was attached by a sort of pedicle and the tonsil could be pushed forward over the cup-like receptacle into the oral cavity for about half an 
incl. The patient informed the interpreter that this accident often happened and caused him much discomfort. The condition was probably congenital and I recommended the removal of the tonsil. The patient did not return.

Case 3. Gunshot wound in mastoid: Patient, a boy about 15 years old, played with a revolver, ( 22 caliber) which was accidentally discharged. 'The bullet entered the mastoid about the middle and ranged inward and upward toward the antrum. Infection occurred and when I saw him at the City Hospital clinic he gave a history of a discharge from the ear since the acciclent, which was several months previous.

A radiogram disclosed that the bullet split, one fragment lodged in the region of the antrum and several small pieces in the mastoid and posterior wall of the canal. I. performed a radical mastoid, and the patient was discharged from the hospital in a few weels, cured.

Case 4. Purpura hemorrhagica: Girl, aged 7 years; American; good home surroundings; looks well nourished but a little pale: teeth normal, had tonsils operated by a surgeon four years ago. About three-fourths of right tonsil was removed and about onehalf of left. Father brought child to see me owing to slight hemorrhage from the throat and for removal of tonsil. Found on examination that the gums were normal. Buccal membrane on right side showed two or three ecchymotic areas which had the appearance of small scratches, purple and pale red. On examining the right tonsil I found it in fairly healthy condition. Left tonsil large and looked as if it had never been operated. The entire tonsil was covered by a pale, purplish-red area but no free hemorrhage. On the posterior lateral wall of the pharynx there were about six ecchymotic areas similar to those on the buccal membrane. There was no history of any of the exanthematous cliseases.

Next examined skin of leg and on each thigh found areas of purplish reddish spots about the size of a No. 1 shot.

Diagnosis made of purpura and referred to internist. Father afterwards told me another ear, nose and throat surgeon advised removal of tonsil after a hasty examination. The father did not tell him of my diagnosis and of course did not consent, knowing what the outcome would be. 'lhe patient was treated by two internists and in about two weeks after I saw her she began to bleed, first from the bladder and then from under the skin, and finally died after two or three weeks.

Metropolitan Building. 


\section{ESOPHAGOSCOPIC RADIUM SCREENS.}

Dr. Chimaliter Jackson, Pittsburgh.

The curative effect of radium in cancer is not yet sufficiently demonstrated to warrant its use in an operable case. But in the inoperable cases of esophageal cancer the results are so encouraging that further testing is justifiable. Efficient screening and large dosage are two essentials. 'The atthor has had such excellent satisfaction with a screen of hard rubber vulcanized on the end of the esophagoscope and on the capsule container as shown in the illustration that it is here published in the hope that it may aid others. With this combination any desired screening can be obtained and

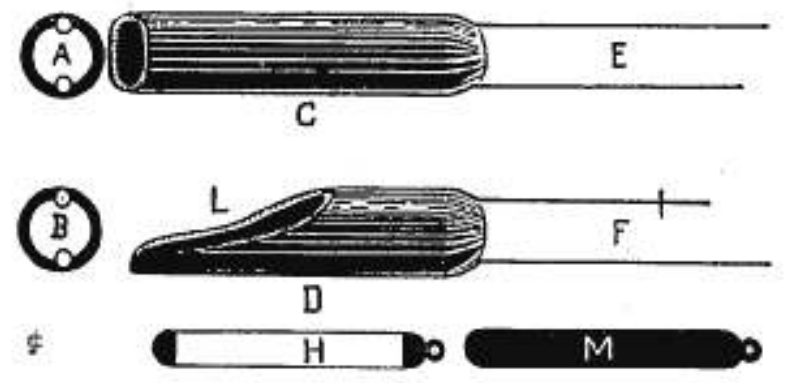

the irritating secondary ray developed on emergence from metal, can be practically entirely cut off; enabling the use of large dosage. With accurate placing under guidance of the eye, burning of healthy tissue can thus be avoided. 'The hard rubber screen can be rulcanized on the end of any form of esophagoscope by any first-class instrument-maker. Being vulcanized to the metal it cannot be accidentally detached. (Figure 1). A covering of hard rubber, C, is vulcanized on to the metal end of the csophagoscope, $\mathrm{E}$. At $\mathrm{L}$, is shown a special form of end arranged with an open side. $A$ and $B$ shows cross-sections of these tubes. $M$ illustrates a capsule entirely covered with hard rubber and at $\mathrm{H}$ is a capstile whose ends only are covered.

Westinghouse Building. 


\section{AN IMPROVED MOUTH"GAG.}

Dr. A. S. Gritin and DR. L. D. GrlitiN, San Francisco.

The mouth-gag devised years ago by Sewall has been a great aid in tonsil operations. It at once acts as a mouth-gag and tonguedepressor and gives a good exposure of the field of operation. Its failure to give iniversal satisfaction is probably due more to its improper use than to any great fault of the instrument itself.

If the blade is too short it will cause buckling of the tongue; if too long it may touch the epiglottis; in either event it may cause gagging or shut-off respiration. Care must be used to adjust the blade just long enough to fit over the base of the tongtue, to rase the

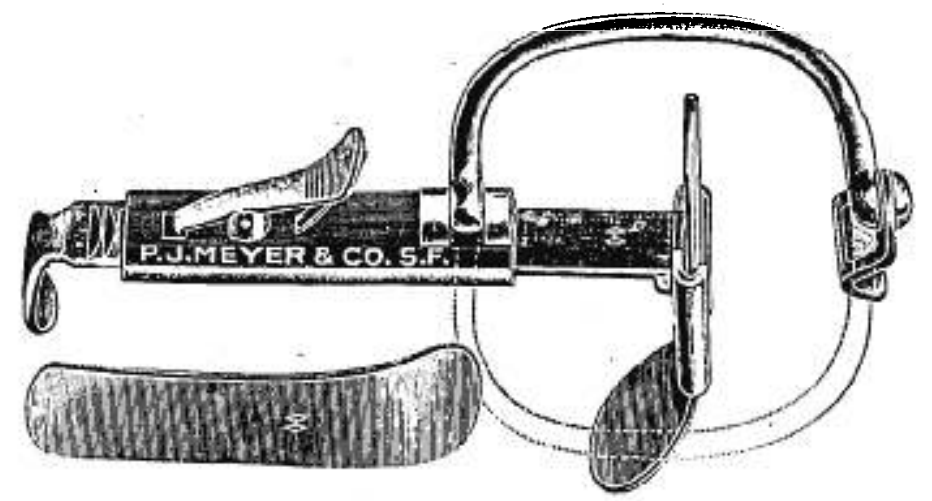

handle to the fullest extent and to maintain it in this position throughout the operation. 'This raises the mandible and permits free respiration.

There are, however, legitimate faults inherent in the instrument and in no way due to faulty manipulation. These objections we have eliminated in the instrument shown in the accompanying illustration.

By substituting a sleeve to hold the tongue-blade for the screwdevice of the Sewall gag, we eliminate an inch or more of metal from projecting into the field of operation. 'This field is further' enlarged by doing away with the rigid cross-bars and utilizing a half arm which can be swtung to either side as necessary without removing the gag from the moutl. The upper teeth are held in a $V$-shaped lead trough, which swings on a pivot. This arrangement avoids breaking the teeth and its adaptibility helps to maintain the gag in the proper position. 
With this instrument many operations can be done that are difficult to do with the older instrument, as for instance the Sluder operation, and the removal of adenoids. Ligating bleedingpoints in the tonsillar fossae becomes easy because it allows a perfect view, so that the vessel can be canght with forceps and the ligature carried clown over it without interference from cross-bars at the angle of the mouth.

Shreve Building.

\section{GOOD RESULTS FROM USE OF NORMAL HORSE SERUM IN A CASE OF HEMORRHAGE FROM A RUPTURED ESOPHAGEAL VEIN. \\ Dr. L̇pwin Cobr, Marshalltown, lowa.}

Mr. A., age 38 years, farmer, Eldora, Iowa, was referred to me by Dr. Koeneman, July 7, 1913. For the last two weeks patient had a very troublesome cough, and yesterday blood was expectorated in amounts varying at times. Patient was brought to this city and placed in the hospital for absolute rest. Examination by both direct and indirect methods revealed a distinct oozing from region of the posterior wall of the esophagus. General examination, negative, especially lungs, and no tendency toward passive congestion. Patient was very anemic, with a distinct pallor present.

In spite of the ordinary measures taken for relief, such as ice bag, absolute rest, calcium chlorid and codcin ifor cough, the oozing continted. 'J'en cem. of normal horse serum was administered hypodermatically. Twelve hours later, $10 \mathrm{ccm}$. more was given in the same manner. The following morning the hemorrhage was much lessened. 'l'wo days later it was completely absent.

Patient was kept in the hospital for one week and then allowed to go home. Two weeks later patient returned stating that he had expectorated a little blood-tinged mucus. 'L'wenty 'cm. of the normal horse serum was administered in separate doses with ab. solute cessation of oozing and at the end of three days patient was discharged and placed under care of general physician. Two months later patient was seen and had gained thirteen pounds; general condition much improved, especially in regard to red cells, with no return of the hemorrhage in any form.

Later, I had occasion to do a nasal operation on a brother; the hemorrhage was far beyond the ordinary. There was evidently a hemophilic tendency in the family.

312 Masonic Temple. 